\title{
Preface
}

\section{The Politics of Sentiment and the Nature of the Real}

This book is an ethnographic exploration of the politics of sentiment at the turn of the twentieth century in Guayaquil, Ecuador. I have used two theoretical constructs-Raymond Williams' (I977) notion of "structures of feeling" and Jacques Lacan's (1977) use of the nature of the Real-to assess the hegemonic ambiguity that develops within historically specific postcolonial contexts such as Guayaquilean identity in Ecuador.

The book is quite ambitious in scope, dealing as it does with issues of identity, politics, sentiment, history, and hegemony. In this sense, it is, above all, a study of the nature of hegemonic production and domination in Ecuador but always maintains a Latin American comparative perspective. The book is thus also a logical extension of my first book, which deals with the role of history in the hegemonic domination of the Latin American nation-state, again using Ecuador as a specific case study. My main objective here is to assess the role of sentiment in its historical production as essential to normative domination in which cultural production is implied and constantly operationalized.

Williams' ( I977) structures of feeling are perfectly positioned to assess the political nature of the production of feeling. Like Williams, I am very much preoccupied with how hegemony works at the level of the particular, not because national hegemonic forms are unimportant but because we know less about how hegemony gets reproduced on a local, day-today scale. At the same time, even national discourse depends on localized production of culture, since, without daily cultural acts, there would be no ideological or material discourses through which to build political projects. The book thus asks how it is that hegemony is operationalized in people's lives. How is it that personal concerns of livelihood, survival, or simply existence are tied to larger historical discursive constraints and 
larger national discourses of domination? Using this line of inquiry, I envision, in a profoundly respectful way, this book as an ethnographic test of Williams' model of structures of feeling.

The evasive issue of life itself is also present in the book, and in my entire research endeavor. This research was fueled by my, and several colleagues', nostalgic figuration of postcolonial Guayaquilean identity. In a social gathering, like many before, between drinks, music, and tears, it became unbearably clear that this form of collective memorialization had to do as much with postcolonial politics as with looking for personal spaces in which to live a bit less burdened and limited by life's beautiful, but chaotic, reality. As a result of this experience, the political nature of sentiment became all the more apparent as well as a socially relevant issue to explore. Admittedly, one of my biggest challenges was to carry out the research in a manner that was conscious of the political dimension of sentiment and yet did not deny the unfathomability and unbearableness of those same feelings, and through them, of life.

It was at this crux that Jacques Lacan's (I977) discourse of the nature of the Real became not only useful but also central in my thinking through the political dimensions of sentiment and their ultimate success as repositories of hegemonic ambiguity. Lacan's idea of the Real allowed me to explore social reality as reality and fiction at one and the same time. According to Lacan, social realities (almost infinite in productive possibilities) are always produced by a profound internal process. The Real is, by its very nature, inaccessible to human knowledge and therefore to social analysis, precisely, perhaps, or even when the Real is implied in a historically informed manner through which particular social realities develop, as in the case of Guayaquilean identity.

I have used primarily Žižek’s (I989, I996, 2002; Žižek, Butler, Laclau 2000) understanding of Lacan's concept of the Real as a central void that occupies the core from which human experience can be understood, since, without this empty center, one would descend into insanity (it is precisely the absence of this void that marks schizophrenia). It is significant, to some degree, that, instead of using Antonio Gramsci's (I97I) and Jacques Lacan's (I977) original formulations, I have decided to use two other theorists who, I believe, have reworked the concepts of hegemony and the Real to bring them closer to our postmodern understanding of the world. Thus, Williams' (I977) and Žižek's (2002) work contribute to rather than merely borrow from Gramsci's and Lacan's original theoretical proposals. These theoretical concerns are made more explicit in the first two chapters. 
I hope that the book will serve as an ethnographic mirror that problematizes sentimental historical production in the articulation of hegemonic domination. I also hope to successfully exemplify domination without destroying or eliminating the ambiguous nature of all cultural (i.e., hegemonic) projects, all the while recognizing the centrality of life in all our social effects as complex and ambiguous human beings. 
THIS PAGE INTENTIONALLY LEFT BLANK 